\title{
Governance by Non-interference and Creating the first-class University ---from examples of Taiwan
}

\author{
Weidong Sun \\ Changzhou College of Information Technology, Changzhou 213164, China \\ e-mail: 815981539@qq.com
}

Key words: Governance by Non-interference; the first-class University; Taiwan

\begin{abstract}
Governance by non-interference is a significant management feature of Taiwan universities, which has such advantages as inspiring innovation, creating core competence, cultivating sustainable development ability, and so on. However, governance by non-interference doesn't mean simply that managers do nothing but act as things are being, that is mangers act only when exceptions appear and usually employees manage themselves. This management method must be on the basis of certain prerequisites: managers don't have a crush on power and employees are highly conscientious of themselves. Obviously, universities, which are used to traditional management modes, can't satisfy wholly such conditions; therefore, they should work hard, firstly, must undergo a heart revolution and adopt this kind of management philosophy. Secondly, execute strict management systems, guide and solid teachers and students to normative behavior habits, and form the culture environment of "pursuit of excellence". Finally achieve management realm of governance by non-interference gradually and achieves the goal of creating the first-class university.
\end{abstract}

\section{Introduction}

The management idea of Governance by non-interference was first proposed by the founder of Taoism Lao-tzu, who said: "man must conform to the earth, earth to heaven, heaven to Tao and Tao to nature." Here, "Tao" refers to the "regularity", and its essence is natural. Because of the natural essence of "Tao", Lao-tzu believed that things should develop according to their nature, not being interfered with, not being forced to influence the natural course of things. However, Governance by non-interference named by Lao-tzu doesn't simply mean "managers need do nothing". "Non-interference" here means "natural", referring not to violating the natural course of things, and "governance" means "management". Therefore, "Governance by non-interference" means "management as the things being, not violating the natural process of things so as to achieve the purpose of smooth management".

\section{Governance by non-interference is a significant characteristic of management of the Taiwan University}

\subsection{Taiwan universities implement objective management to teachers}

Most of Taiwan Universities carry out the objective management method to manage teachers. In the earlier time of a year, teachers are set specific objectives agreed upon by primitive consultation, including scientific research, theoretic teaching, practice teaching and student education, which are qualitative and quantitative objectives and the latter accounts heavily. Usually teachers are rarely checked by the school but sometimes may obtain some help when they happen to meet incidents. When a year draws near, universities will check the teacher's performance according to the objectives set in the earlier time of the year one by one.

Although Taiwan Universities implement objective management methods, and usually teachers are checked rarely, but the daily teaching can keep in order by the use of the "28 management" principle, which attaches great importance to the key points basically reflecting the teaching and research status. For example, universities attach great importance to student feedback through the 
network survey, student forum etc., and the problem found will be resolved in a timely manner by communication with teachers. Universities will ask teachers about the progress of their scientific research in a certain time (Note: not check), and help teachers solve the difficulty to ensure the smooth schedule of their annual objectives.

\subsection{Taiwan universities implement the "red line" management to students}

A lot of Taiwan universities have no class supervisor or counselor, so students have not being looked at or told to do something all the day round, and students mainly carry out self management. Students seem busy all time learning or participating in various community activities organized by the students themselves. As to the daily cultivation education, such as daily civilization, politeness, hygiene or other aspects, it seems blank in Taiwan universities.

However, the behavior freedom of college students in Taiwan is delineated within the discipline of the red line, and once some students cross the red line, they will be punished very seriously and ruthlessly. For example, without permission of the dormitory administrator, if male and female students channel each dormitory, smoke on the campus corner or have some other seemingly minor violations, they are sure to get severe penalties, and the execution will be carried out to the full.

In fact, Taiwan universities implement the "red line" management of "permitting doing everything that no law forbids", which gives students full freedom of activities, fully stimulates students' ability of self innovation, self discipline and self management, and at the same time, achieves the effect of "governance by non-interference".

\section{Taiwan Universities carry out open campus management to societies}

Many Taiwan Universities' campus and parking lot are open to society all day long, which means there is no doorman or guard in supervision of school gate and anyone can freely walk in and out of school and put their vehicles in the parking lot. Although Taiwan Universities always send several persons to guard places related to personal privacy or security, such as student dormitory, library and other fields, the general public facilities or places, such as the playground, gymnasium, stadium, and cafeteria are undefended and full open to societies. This loose campus management looks like existing many potential security risks, but the fact, on the contrary, is not like that. Really some nearby residents often come and have a walk or play basketball on campus, and so on, and they get along well with the students, which makes people feel that Taiwan Universities treat the societies friendly, not only attaining good management result of security campus, but also making the school and the society truly integrated, students adapt society truly seamless, the school spend no money on image advertising.

\section{4. the University Characteristics built by management model of Governance by non-interference}

\subsection{Stimulate the innovative ability of teachers and students}

"Nothing can be accomplished without norms or standards."But the rule can not only regulate people's actions, but also restrain people's innovation attempts, so it has a strong utilitarian and purpose. If the rules are too complicated, and administration is so rigid to implement such policies that people are asked to follow norms just like a robot and must not make any mistakes. In result, people's creative ability will be blank and the organization will be like a dead river. The university is the birthplace of new ideas, new thinking, new culture, so any management methods can bind people's open and innovative minds so that teachers and students can tend to develop a full of imagination which will greatly stimulate their individual talents and innovation. To ask students comply with the system and meantime tolerate their mistakes occasionally is the wise attitude of a university administration, and relatively loose management environment is the source of university innovation. 


\subsection{Build university core competence and sustainable development ability}

Core competence is "integration of knowledge and skills within an organization". [2] Core competitiveness of a university does not lie in how many buildings it own, or how many masters and outstanding graduates it own, but in whether it has created the management mechanism to create or cultivate masters and outstanding students, because masters and students have always the life cycle, but the management mechanism can be sustainable. With such a management mechanism, universities will continue to emerge a large number of masters and outstanding students, and such a university will have the real core competitiveness and sustainable development ability.

\section{Steps of "Governance by non-interference" to create the first-class university}

\subsection{To establish the philosophy of "Governance by non-interference"}

The management idea of "Governance by non-interference", as the highest level of management, has undoubtedly a special effect. When this management system is applied to universities, universities must respect teachers and students, and do not interfere too much in their work and study. Especially to students, universities should tolerate their mistakes, and fully trust that majority of students are able to develop, adjust, correct mistakes, manage themselves (that is, they in themselves have the ability of Taoism).

\subsection{To lay the base of implementing "Governance by non-interference" management mode}

As a Chinese crystallization of ancient culture, the "Governance by non-interference" management mode should be brilliant in the land of great China. But how can we attain such an ideal state?

\section{(1)To set "non-interference-oriented" university management systems}

Several principles should be followed: (1) Management system cannot become the fetters of innovative behavior. "The biggest benefit of Governance by non-interference" is to encourage innovation, and the less members of the organization are interfered by the upper management, the more they can maximize their initiative and creativity. (2)The management system must withstand the test of time. (3) The system formulation should follow the principle of "bottom-up" and "top-down". (4) mastering adequate elasticity of scientific systems. As the saying goes, a cowshed cannot keep a cat. If the system is too general, it is easy to have loopholes and easy to be taken advantage by someone. But if the system is so rigid that it has little flexibility, it is not only easy to control people but also kill cherish innovation.

\section{(2)To implement strictly university management systems}

If it is said to be difficult to establish a complete and scientific management system, it is of much more difficult obstacle to implement the "Governance by non-interference" management. Even if "High voltage line" is erected, but if it is not turned on "electric", it is not available. Similarly, once the strict management systems are formed, they must be strictly enforced, or they cannot function at all. A system without execution is more harmful than without a system.

Obviously, to achieve the state of "Governance by non-interference", the domestic university cannot completely copy foreign or overseas universities' management way in which students are managed just like herding sheep. But domestic universities can never continue to manage students as before as teachers and students were under surveillance and supervision every hour and moment, and there should be less didactic, more punishment so as to completely eliminate all kinds of fluke mind to violate discipline, so as to truly develop the habit of consciously abiding by the management.

(3) To create a university management culture of "Governance by non-interference"

The "human-oriented" is the basis of "Governance by non-interference", and no trust in the majority of teachers and students is undesirable behavior. But blindly trust is more dangerous, for those who have formed the bad behavior habit must be seriously supervised, and only after a certain stage of the "strict management", can the management of "Governance by non-interference" effect. However, here the "serious supervision" no longer refers to supervision and command every hour 
and moment, but the check and help in key points and for their final performance evaluation, the control system must be strictly enforced, and even minor error must not be tolerated.

\subsection{To steadily promote "Governance by non-interference" management mode}

Through above system construction and cultural construction, the university may meet the basis of implementing "Governance by non-interference" management mode, and most of the students can consciously abide by the rules and regulations, but there must be a part of the students who are habitual drunkards. Therefore, in the next stage, the university should steadily promote "Governance by non-interference" management mode, and cannot completely copy the Taiwan model. The social factors are an obstacle in "Governance by non-interference" management mode. Many people mistakenly believe that the loose management is irresponsible, and the university should bear total responsibility if students have accidents at school. In fact, college students are adults having the capacity for civil conduct, and it is inevitable that students have some occasionally accidents at school. If the responsibility should be shouldered by the university, the university should no doubt shoulder it. Otherwise the university shouldn't take the responsibility. The university should not give up "Governance by non-interference" management mode because of fearing accidents happening to students.

\section{Summary}

The stone of his mountain, can offend jade. But when going abroad or overseas, Chinese universities cannot simply imitate or copy others' seemingly good practices, otherwise the consequences can only be bad. The most important thing is that universities can not only see the benefits of their practices, but also make clear the preconditions for this practice and understand the mechanism of action. Taiwan Universities' "Governance by non-interference" management mode is good, but the development level of our universities does not allow us to fully implement the management mode, but this kind of management philosophy should be rooted in our universities' management minds, and now domestic universities should make an effort on strict management, standard behavior, good habits, to gradually achieve the management basis, and finally by gradually implementing "Governance by non-interference" management mode to achieve the goal of building a first-class university".

\section{Acknowledgement}

This research was financially supported by Jiangsu provincial excellent innovative team of philosophy and Social Sciences (Grant NO. 2017ZSTD035), China Association of Higher Education (Grant No. GZYZD2017008), Vocational Colleges' Foreign Major Direction Committee of Ministry of Education of the People's Republic of China (Grant No.GZWYJXGG-036), Changzhou College of Information Technology's key humanities and Social Sciences project (Grant No. CXRS201704Z), and Changzhou College of Information Technology's teaching reform project (Grant No.3196)

\section{Reference}

[1] Lao Zi, Tao Te Ching[M], China Daily Press, 2012

[2] Gao Chunjing, core competitiveness[M], Research Press, 2011

[3] Douglas McGregor, The Human Side of Enterprise[M]. Washington Press, 1992

[4] Zhou Jianbiao, A middle course enthusiasm and its limitations [J]. Journal of Chongqing Jiaotong University (SOCIAL SCIENCE EDITION), 2012.01 